\title{
Interplay between CCR7 and Notch1 axes promotes stemness in MMTV-PyMT mammary cancer cells
}

\author{
Sarah T. Boyle ${ }^{1,2}$, Krystyna A. Gieniec $^{2}$, Carly E. Gregor², Jessica W. Faulkner², Shaun R. McColl²
} and Marina Kochetkova ${ }^{1,2^{*}}$ (iD

\begin{abstract}
Background: Breast cancer is the major cause of cancer-related mortality in women. It is thought that quiescent stem-like cells within solid tumors are responsible for cancer maintenance, progression and eventual metastasis. We recently reported that the chemokine receptor CCR7, a multi-functional regulator of breast cancer, maintains the stem-like cell population.

Methods: This study used a combination of molecular and cellular assays on primary mammary tumor cells from the MMTV-PyMT transgenic mouse with or without CCR7 to examine the signaling crosstalk between CCR7 and Notch pathways.

Results: We show for the first time that CCR7 functionally intersects with the Notch signaling pathway to regulate mammary cancer stem-like cells. In this cell subpopulation, CCR7 stimulation activated the Notch signaling pathway, and deletion of CCR7 significantly reduced the levels of activated cleaved Notch1. Moreover, blocking Notch activity prevented specific ligand-induced signaling of CCR7 and augmentation of mammary cancer stem-like cell function.

Conclusion: Crosstalk between CCR7 and Notch1 promotes stemness in mammary cancer cells and may ultimately potentiate mammary tumor progression. Therefore, dual targeting of both the CCR7 receptor and Notch1 signaling axes may be a potential therapeutic avenue to specifically inhibit the functions of breast cancer stem cells.
\end{abstract}

Keywords: Breast cancer, Mammary gland, Chemokine receptor, CCR7, Notch, Cancer stem cell, Crosstalk

\section{Introduction}

Despite significant recent advances in breast cancer treatment, breast cancer is still the major cause of cancer-related death in females worldwide. Resistance to radiation and chemotherapy, together with unpredictable recrudescence, are the most challenging issues in clinical practice. Significant evidence has accumulated in recent years to implicate cancer stem-like cells (CSCs) as the main perpetuators of cancer recurrence and therapy resistance in mammary and other tumors, as this cell population exhibits stem cell-like characteristics of selfrenewal, quiescence and the ability to differentiate into

\footnotetext{
* Correspondence: marina.kochetkova@unisa.edu.au

${ }^{1}$ Centre for Cancer Biology, University of South Australia and SA Pathology, Adelaide, SA, Australia

${ }^{2}$ Department of Molecular and Cellular Biology, School of Biological Sciences,

University of Adelaide, Adelaide, SA, Australia
}

various cell lineages [1, 2]. Therefore, targeting alterations acquired by CSCs in stemness-related signaling pathways has been proposed as an effective therapeutic strategy to counteract current treatment shortfalls in breast cancer management. However, CSC regulatory mechanisms remain largely undiscovered.

Chemokine receptors and their ligands have been implicated in numerous aspects of breast malignancy [3]. The chemokine receptor CCR7 and its ligands CCL19 and CCL21 have been associated with metastasis, poor survival, invasion and cell migration in primary tumors and breast cancer experimental models [4-6]. We have recently shown that CCR7 regulates stem cell-like activity in primary mammary tumors in mice and humans [7], and sought to understand how CCR7-mediated stemness interacts with and/or is influenced by recognized stem cell-related signaling pathways. 
The Notch pathway is one of the major signaling axes in embryonic and adult stem cell homeostasis and has a critical role in regulating proliferation, differentiation, apoptosis, cell-cell communication and other multiple functions [8, 9]. Notch receptors are proteolytically cleaved in a two-step process, releasing the intracellular domain that translocates to the nucleus and acts as a transcriptional cofactor for various genes including those mediating cell fate [10]. A cancer-specific role of the Notch axis has also been extensively studied in both solid and blood neoplasms, and numerous inhibitors of $\gamma$-secretase - the enzyme that cleaves and hence activates Notch signaling - are now being trialed in human patients as anti-cancer drugs [11, 12]. Notably, Notch has been reported to play both oncogenic and tumorsuppressive roles depending on the cell type and tissue context [10], thus warranting further investigation into molecular determinants of the tumor-promoting or tumor-inhibiting arms of this complex, multifaceted signaling pathway.

Signaling through the Notch axis has been reported to crosstalk with multiple other pathways including numerous oncogenic mediators, such as Wnt effectors [13], the Hedgehog pathway, cytokines, kinases and growth factors in mammary and other cancers [14, 15]. Of note is the intersection between the epidermal growth factor receptor (EGFR) system and Notch pathway that has been proposed as a mechanism for trastuzumab resistance in HER2-positive tumors, and thus a route for therapeutic intervention [16]. Effectively, the identification of specific crosstalk networks of Notch that govern growth and differentiation of mammary cancer cells may provide new opportunities for developing effective inhibitors of tumor relapse and metastasis.

As Notch pathway members have been implicated in maintenance of stem cell pools within mammary tumors [17-19], and having previously found that activation of CCR7-mediated signaling also promotes stemness [7], we hypothesized that these pathways may interact within breast CSC pools to enhance and maintain tumor cell stemness properties. Using the MMTV-PyMT mouse model, we show here that CCR7 and Notch1 cooperate and crosstalk within transformed mammary stem celllike compartments, indicating that the CCR7-Notch axis may be a potential target for therapeutic intervention in breast cancer.

\section{Materials and methods}

Mice

MMTV-PyMT; $C c r 7^{\mathrm{WT}}$ (referred to as PyMT-Ccr $7^{\mathrm{WT}}$ ) and MMTV-PyMT; $C c r 7^{-1}$ (referred to as PyMT$C \mathrm{Cr} 7^{-1-}$ ) mice on a pure $\mathrm{C} 57 \mathrm{BL} / 6$ background were generated and described previously [7]. The University of Adelaide institutional animal ethics committee approved all protocols.

\section{Mammary cell extraction}

Mammary epithelial cell extraction was performed as described [20]. Briefly, mouse mammary glands/tumors were dissected, manually dissociated and then digested in Dulbecco's modified Eagle's medium (DMEM, Gibco) supplemented with $1 \mathrm{mg} / \mathrm{ml}$ collagenase, $100 \mathrm{U} / \mathrm{ml}$ hyaluronidase (both from Worthington) and $2 \%$ foetal calf serum for $3 \mathrm{~h}$ at $37{ }^{\circ} \mathrm{C}$. Resultant organoids were digested a further $15 \mathrm{~min}$ with $6 \mathrm{U} / \mathrm{ml}$ dispase (Gibco) and $12 \mathrm{U} / \mathrm{ml}$ DNase I (Merck) at $37{ }^{\circ} \mathrm{C}$. Cells were filtered through a $70 \mu \mathrm{m}$ nylon mesh to obtain a single cell suspension.

\section{Mammosphere culture}

Mammosphere cultures were established by seeding freshly extracted mammary cells in complete sphere medium (1:1 volumes of DMEM and Ham's F12 nutrient mix (Gibco) supplemented with 1× B27 (Invitrogen), $10 \mathrm{ng} / \mathrm{ml}$ epidermal growth factor ( $\mathrm{R} \& \mathrm{D}$ Systems), $20 \mathrm{ng} / \mathrm{ml}$ basic fibroblast growth factor ( $\mathrm{R} \&$ D Systems), $4 \mathrm{ng} / \mathrm{ml}$ heparin (Sigma Aldrich), and 1\% penicillin-streptomycin) to polyhema-coated plates. After 7 days, mammospheres were passaged by centrifuging at 200xg for $5 \mathrm{~min}$, resuspended in trypsin/ EDTA and triturated through a $19 \mathrm{G}$ needle to break up colonies. Cells were filtered through $70 \mu \mathrm{m}$ and washed extensively before re-seeding for secondary culture in complete sphere medium. For all assays, secondary cultures were analyzed. Where specified, spheres were cultured in the presence of $\gamma$-secretase inhibitor RO4929097 (SelleckChem) at 50nM, Wnt/ $\beta$-catenin inhibitor XAV-939 (SelleckChem) at $1 \mu \mathrm{M}$, CCL19 at $200 \mathrm{ng} / \mathrm{ml}$, and CCL21 at $10 \mathrm{ng} / \mathrm{ml}$. For analysis of mammosphere-forming efficiency, secondary spheres were assessed for number of spheres formed per cells seeded.

\section{Flow cytometry and FACS}

Flow cytometry/FACS was carried out by blocking for non-specific binding for $15 \mathrm{~min}$ at room temperature in mouse $\gamma$-globulin in PBS/0.5\% bovine serum albumin (BSA) followed by immunostaining for 30-45 $\mathrm{min}$ on ice in PBS $/ 0.5 \%$ BSA. Primary anti-mouse antibodies used were anti-Notch1ECD-APC, biotinylated antiNotch1ICD (eBioscience), anti-CD24-PE, anti-CD29-PE, anti-CCR7-AlexaFluor647 (BD Biosciences), anti-CD24FITC, anti-CD24-PE/Cy5 (Life Technologies), antiCD29-FITC, anti-CD29-AlexaFluor647, anti-Jagged1-PE and anti-DLL1-AlexaFluor647 (BioLegend). For Notch1ICD, cells were permeabilized prior to labelling followed by detection using streptavidin-AlexaFluor488 (BD 
Biosciences) in $\mathrm{PBS} / 0.5 \% \mathrm{BSA}$ for $30 \mathrm{~min}$ on ice. Fluorescence-minus-one (FMO) controls for each antigen in multi-color analysis were used for negative gating. MFI = mean fluorescence intensity.

\section{Western analysis}

Proteins were separated by $10 \%$ SDS-PAGE and immobilized onto nitrocellulose membrane. Western analysis was performed as previously described [21]. The $\gamma$-secretase inhibitor RO4929097 (SelleckChem) was used at 50nM and CCL19 at $200 \mathrm{ng} / \mathrm{ml}$ and times of treatment are specified in the figures and figure legends. Primary antibodies used were anti-Notch1 ICD (Abcam), anti-Hes1 (R \& D Systems), anti-phospho-ERK, anti-ERK1/2 (both from Cell Signaling Technology) and anti- $\beta$-Actin (Sigma-Aldrich). Band intensities were calculated using Image J.

\section{Cyclic AMP analysis}

cAMP levels were measured using an AlphaScreen cAMP Assay Kit (Perkin-Elmer) as per manufacturer's instructions. The $\gamma$-secretase inhibitor RO4929097 (SelleckChem) was used at 50nM, CCL19 at $200 \mathrm{ng} / \mathrm{ml}$, and CCL21 at $10 \mathrm{ng} / \mathrm{ml}$. Cells were treated for $30 \mathrm{~min}$ before analysis.

\section{mRNA analysis}

Total RNA was extracted using an RNeasy Kit (Qiagen) and reverse-transcribed using the Transcriptor First Strand Kit (Roche), followed by quantitative PCR analysis using the SYBR Green method. Samples were normalized to endogenous ribosomal protein Rpl32. qPCR primer sequences are as follows:

\begin{tabular}{lll}
\hline Gene & Forward Primer 5'-3' & Reverse Primer 5'-3' \\
\hline Hes1 & TCCAAGCTAGAGAAGGCAGAC & TGATCTGGGTCATGCAGTTG \\
Ccr7 & CATTGCCTATGACGTCACCTACA & GAAGGCATACCAGAAAGGG \\
& & TTGA \\
CC119 & CTGCCTCAGATTATCTGCCAT & CTTCCGCATCATTAGCACCC \\
CC121 & GCAAAGAGGGAGCTAGAAAACA & TGGACGGAGGCCAGCAT \\
& GA & \\
Rpl32 & AAGCGAAACTGGCGGAAAC & TAACCGATGTGGGCATCAG \\
\hline
\end{tabular}

\section{Statistics}

Data are mean \pm SEM and results are representative of at least 3 independent experiments. Significant statistical differences were estimated using Student's t-tests or ANOVA and significant associations between CCR7 and Notch1 were identified using Pearson correlation coefficients. $P$-values were used to denote statistical signifi-

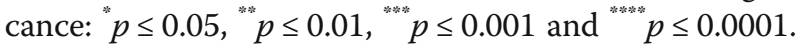

\section{Results}

CCR7 activates the Notch1 signaling pathway in mammary cancer stem-like cells

In the search for mechanistic clues of the CCR7mediated augmentation of the mammary stem cell compartment, we investigated crosstalk between CCR7 and Notch1 pathways, as Notch1 signaling has also been implicated in mammary cancer stem cells [17]. The Notch intracellular domain is released upon receptor activation and acts as a transcriptional cofactor to promote stemness [10], therefore we examined the levels of Notch1 receptor domains in the $\mathrm{CD} 24^{+} \mathrm{CD} 29^{\text {hi }}$ stem cellenriched population $[22,23]$ from PyMT-Ccr $7^{\mathrm{WT}}$ and PyMT-C $\mathrm{Cr}^{-1-}$ murine mammary tumors. The CD24 ${ }^{+} \mathrm{CD} 29^{\text {hi }}$ gating strategy we have employed for all multicolor flow cytometry throughout the study is shown in Additional file 1: Figure S1a. While CCR7 did not affect cell-surface expression of Notch1 (Fig. 1a), levels of the Notch1 intracellular domain (N1ICD) were significantly reduced in CCR7-null stem-like cells (Fig. 1b). This finding was substantiated by results obtained in secondary mammospheres (that are enriched for stem and progenitor cells [24]) from PyMT-Ccr $7^{\mathrm{WT}}$ tumors, as stimulation of CCR7 with its ligand CCL19 significantly increased levels of N1ICD over time (Fig. 1c). Expression of common Notch ligands DLL1 and Jagged1 was not affected by CCR7 (Additional file 1: Figure S1b and c), and hence findings were not due to an alteration of Notch ligands on CSCs, but rather Notch1 itself. Taken together, these data indicate that Notch1 cleavage is significantly potentiated by CCR7.

To establish if CCR7-mediated regulation of the Notch pathway is functional, we tested the levels of Notch transcriptional target Hes1 [10]. Both Hes1 mRNA and protein levels were significantly reduced in CCR7-null cancer stem cell-like populations (Fig. 2a and b), either sorted for $\mathrm{CD} 24^{+} \mathrm{CD} 29^{\text {hi }}$ expression by FACS or selected through culturing as secondary mammospheres. Importantly, direct stimulation of PyMT-Ccr $7^{\mathrm{WT}}$ mammospheres through culturing in the presence of either CCL19 or CCL21 greatly increased Hes1 expression (Fig. 2c), validating results obtained with the CCR7-null cells. Furthermore, Hes1 regulation by CCR7-cognate chemokines was receptor specific as it was not seen in PyMT-Ccr $7^{1-}$ cells (Fig. 2d). These results suggest that CCR7 regulates expression of Notch target stemness-promoting genes, and thus CCR7-mediated functional properties of stemness may involve Notch pathway activity.

\section{Notch mediates CCR7-promoted stemness in mammary cancer cells}

As Notch activation requires proteolytic cleavage by $\gamma$ secretase, we utilized the $\gamma$-secretase inhibitor RO4929097 (previously used in breast cancer studies to inhibit Notch 

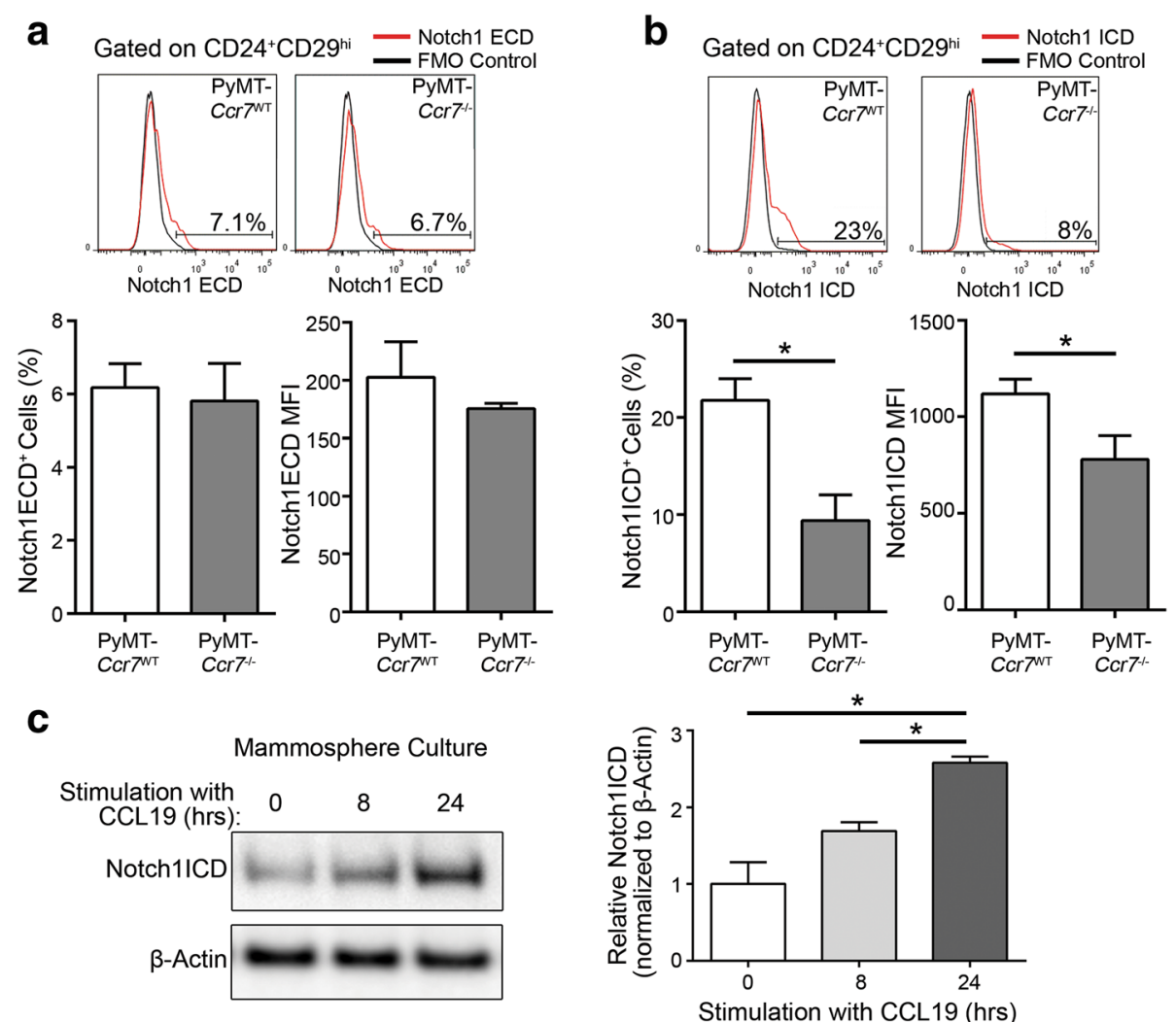

Fig. 1 Cleavage of Notch1 in mammary cancer stem-like cells is dependent on CCR7. a-b Primary PyMT-Ccr $7^{\mathrm{NT}}$ and $\mathrm{Ccr} 7^{-1-}$ mammary tumor cells were analyzed by multi-color flow cytometry for Notch1 expression within the stem cell-enriched population $\mathrm{CD} 24^{+} \mathrm{CD} 29^{\text {hi }}$. Top $=$ representative flow cytometry plots, bottom = quantification. a Notch1 extracellular domain (ECD) cell surface expression in the PyMT-Ccr $7^{\mathrm{NT}}$ and $\mathrm{Ccr} 7^{1-}$ mammary stem cell-like population. b Notch1 intracellular domain (ICD) levels in the PyMT-Ccr $7^{\mathrm{WT} T}$ and $\mathrm{Ccr} 7^{-1-}$ mammary stem cell-like population. Bulk tumor cells were first labelled for extracellular CD24 and CD29 before permeabilization and staining for Notch1 ICD. $\mathbf{a}-\mathbf{b} n=4$ mice/genotype. FMO =fluorescence minus one, MFI = mean fluorescence intensity. c Notch1 ICD levels in PyMT-Ccr $7^{\mathrm{WT}}$ secondary mammospheres, stimulated with CCL19 for varying lengths of time as indicated before lysis for Western analysis. $n=6$ mice/experiment

signaling [25]) to examine the effect of CCR7 on mammary cancer stem cells in the context of Notch activity blockade. The effect of RO4929097 in secondary PyMT$\mathrm{Ccr} 7^{\mathrm{WT}}$ mammospheres was first verified by examining Hes1 expression, which was significantly reduced by addition of the inhibitor (Additional File 1: Figure S2a). Notably, we found that treatment with RO4929097 did not affect expression of CCR7 or its ligands CCL19 and CCL21 (Additional File 1: Figure S2b-d), in contrast with other studies in leukemic cells [26].

We then assessed the effect of RO4929097 on the function of CCR7 in mammary stem-like cells. We found that inhibition of cyclic AMP (cAMP), a read-out for chemokine receptor activity but not a known outcome of Notch signaling, was induced by CCL19 and CCL21; however addition of RO4929097 abrogated this chemokine-mediated inhibition of forskolin-induced cAMP (Fig. 3a).

To further confirm that the CCR7 pathway interacts with Notch signaling, we analyzed mammosphere growth after addition of CCL19 and CCL21 with and without RO4929097. We observed that blocking $\gamma$-secretase significantly inhibited CCL19-mediated phosphorylation of ERK, an effector of CCR7 signaling that is not downstream of Notch itself (Fig. 3b). Notch also affected the ability of CCR7 to stimulate mammosphere formation. In concordance with a previous study [27] RO4929097 reduced secondary mammosphere formation. The addition of CCL19 or CCL21 was not sufficient to restore mammosphere formation to levels seen with chemokine stimulation alone (Fig. 3c), suggesting that inhibition of Notch inhibits the stemness-promoting function of CCR7. However, mammosphere formation was partially rescued, indicating that there are other Notch-independent pathways in play in this context.

We observed that the other major signaling pathway previously implicated in stem cell maintenance, Wnt/ $\beta$ catenin [28], did not impact upon CCR7-mediated stemness as the Notch pathway appears to. Specifically, while 

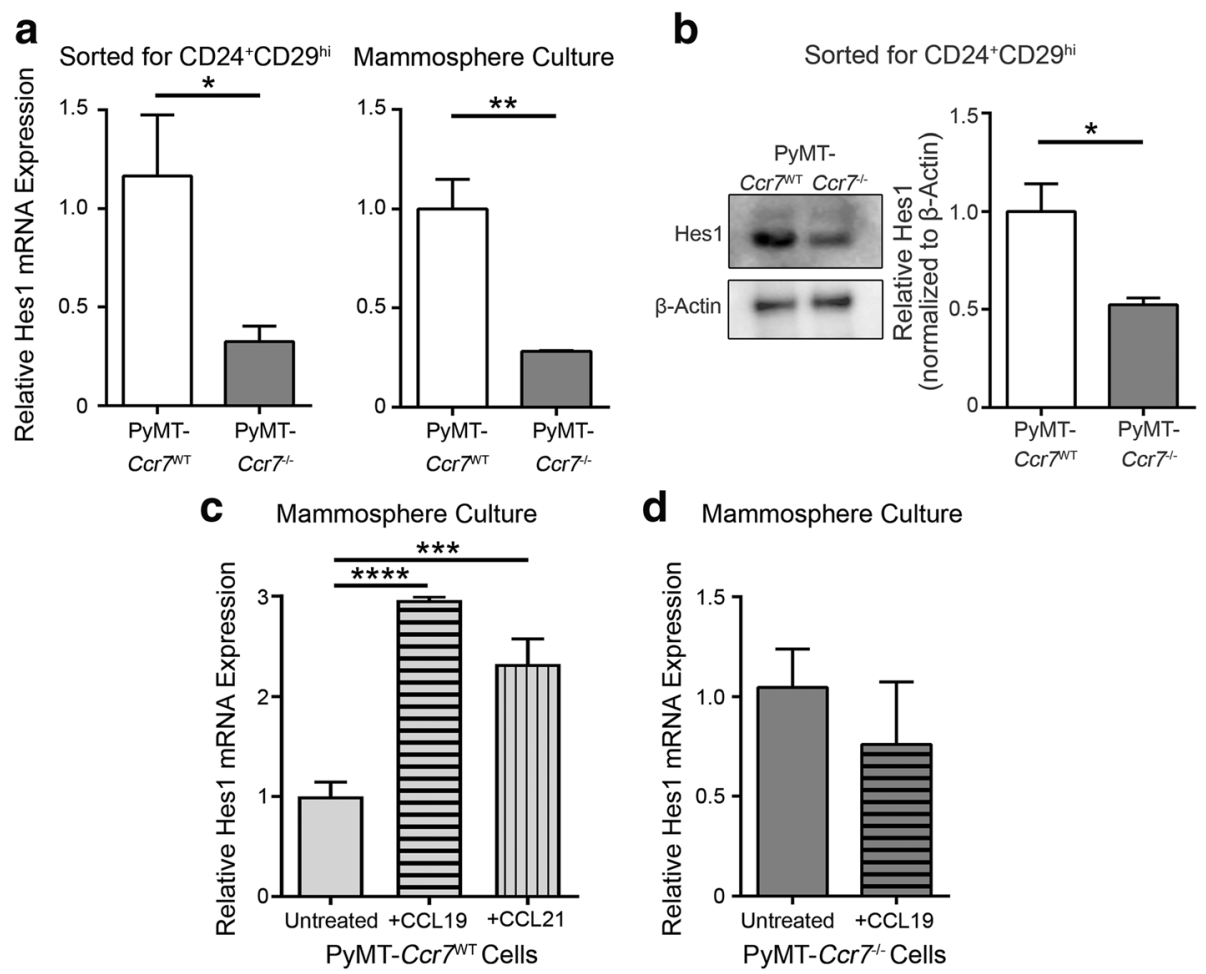

Fig. 2 CCR7 activates the Notch signaling pathway in mammary cancer stem-like cells. a-b Hes 1 expression was assessed in primary mammary CSCs from PyMT-C Cr $7^{\mathrm{WT}}$ and $\mathrm{CCr}^{-1-}$ tumors. a Hes1 mRNA levels relative to PyMT-C $\mathrm{Cr} 7^{-1-}$ in the sorted $\mathrm{CD} 24^{+} \mathrm{CD} 29^{\text {hi }}$ stem cell-enriched population (left) and in secondary mammospheres (right), $n=4-6$ mice/genotype/experiment. b Hes1 protein expression in the CD24 ${ }^{+} C D 29^{\text {hi }}$ sorted cell population, $n=4$ mice/genotype. c Relative Hes1 mRNA levels in PyMT-C Cr $7^{\mathrm{WT}}$ secondary mammospheres cultured with and without CCL19 and CCL21. d Relative Hes1 mRNA levels in PyMT-CcrT ${ }^{--}$secondary mammospheres cultured with and without CCL19. $\mathbf{c}-\mathbf{d} n=6$ mice/experiment

inhibition of Wnt signaling with the specific inhibitor XAV-939 significantly decreased sphere-forming ability and hence stemness properties in primary PyMTexpressing tumor cells as expected [29], addition of the CCR7 ligand CCL21 to XAV-939 treated cells was sufficient to restore sphere formation to that seen when stimulated with CCL21 alone (Additional File 1: Figure S3), thus demonstrating that the Wnt pathway is not involved in CCR7-mediated regulation of stem cell maintenance.

These data show that the function of CCR7 in promoting the stemness of mammary tumor cells is partly mediated through Notch signaling. Although CCR7 regulates Notch1 activation in MMTV-PyMT tumor cells, the two pathways likely cooperate to promote CSC activity.

\section{Discussion}

Despite advances in clinical treatment of breast cancer, recurrence remains a significant problem due to the survival of quiescent cancer stem cells. Novel combination therapies against CSCs, acting as adjuvants together with conventional approaches, are therefore needed. We previously demonstrated that the chemokine receptor
CCR7 promotes mammary tumorigenesis via amplification of stem-like cells [7], and we now show here that crosstalk between Notch and CCR7 signaling promotes breast cancer stemness and may be a potential target for these new therapies.

Notch can have opposing roles depending on biological context, with Notch1 activation shown to both perpetuate and inhibit cell differentiation [10]. Notch also regulates, and is regulated by, different chemokine receptors. In acute lymphoblastic leukemia, Notch1 regulates cell proliferation and migration through CCR5 and CCR9 [30], and in multiple myeloma Notch regulates CXCR4 [31]. While no functional crosstalk between the two pathways has been reported so far, it was suggested that Notch activation up-regulates CCR7 expression in leukemic cells [26]. However, in TCR-activated peripheral blood mononuclear cells CCR7 expression was slightly increased following Notch inhibition with RO4929097 [25]. In breast cancer, CCL2 secreted from cancer-associated fibroblasts induces a CSC phenotype by activating Notch signaling, highlighting the concept that crosstalk may exist between the two axes [32]. Plausibly, the interplay between CCR7 and Notch is adaptable in different systems. 


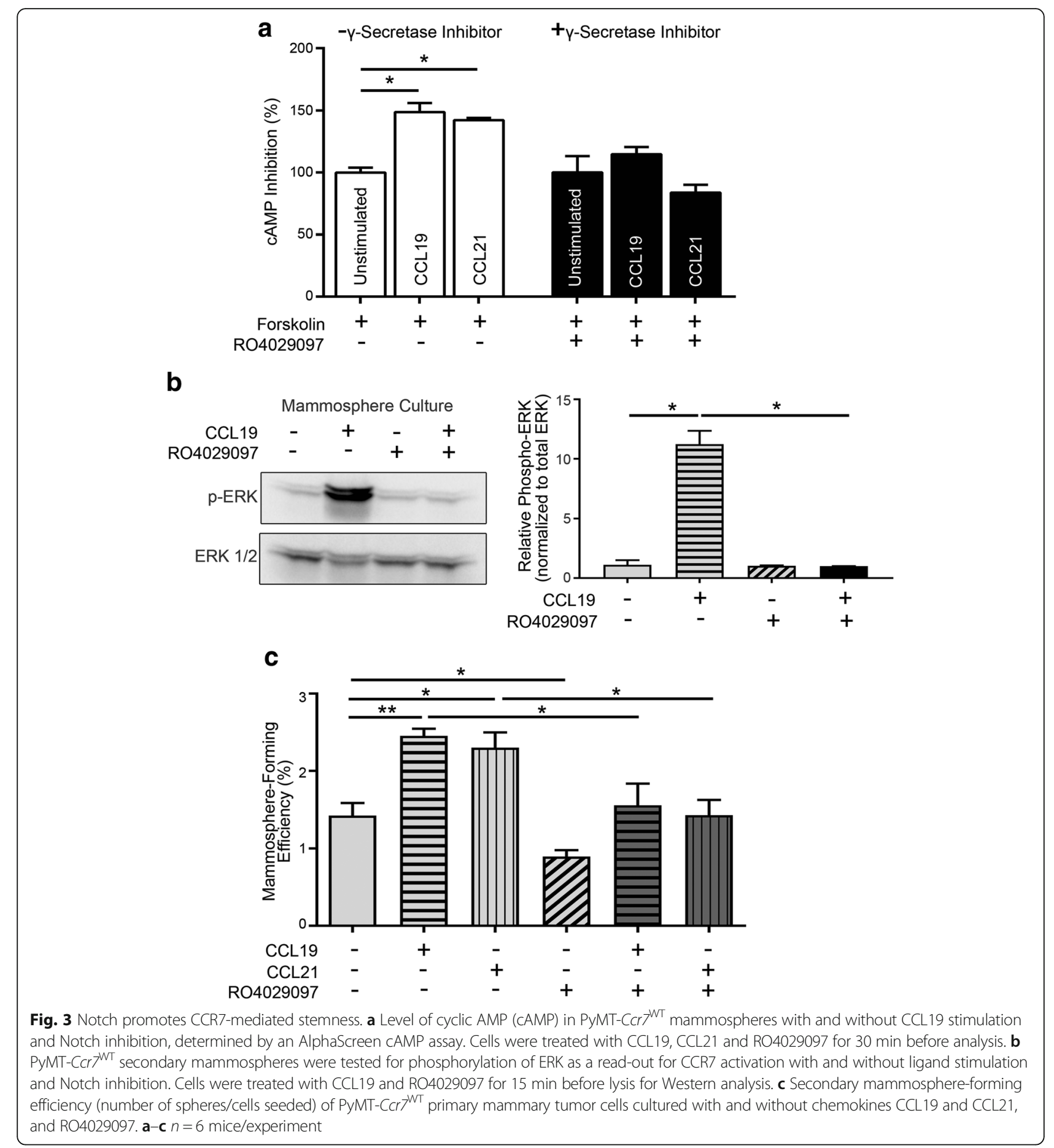

In this study, we have demonstrated that the deletion of CCR7 significantly decreases levels of activated Notch1, and conversely, stimulation of the CCR7 pathway increases Notch receptor activation and expression of downstream target genes. We did not find any substantial Notch-mediated regulation of CCR7 receptor or ligand expression but observed a significant crosstalk at the functional level, which was not seen with the other major signaling pathway involved in stem cell maintenance, Wnt/ $\beta$-catenin [28]. Notably, unlike other cellular types such as lymphocytes that display differential-ligand induced CCR7 signaling and functional events [33] the observed CCR7 effect upon stemness is not ligandspecific, as we observed similar results for both CCL19 and CCL21. 
Importantly, these findings may be translatable to human disease, as analysis of a published database available in Oncomine [34] showed that expression of CCR7 and Notch 1 are significantly correlated in primary human breast cancers, particularly in higher grade tumors (Additional File 1: Figure S4). Although Notch proteins are known to regulate stemness, and CCR7 to promote tumorigenesis through a number of pathways, to the best of our knowledge this is the first study linking Notch1 to CCR7-dependent regulation of stem-like cells in mammary cancer. This novel phenomenon opens up the avenue for concurrent therapeutic targeting of these pathways. Antagonists towards CCR7 are capable of reducing stem-like cell content and activity [7], and $\gamma$ secretase inhibitors and antibodies that block the Notch pathway have also been shown to specifically target tumor-initiating cells $[35,36]$. This approach may therefore be a new opportunity for targeting evasive cancer stem cells to control breast cancer progression.

\section{Additional file}

Additional file 1: Supplementary Figures. (PDF 17190 kb)

\section{Acknowledgements}

The authors are grateful to Associate Professor Michael Samuel for critique of the manuscript.

\section{Funding}

This work was supported in part by a Project Grant from the National Health and Medical Research Council, Australia. The funding body did not play a role in the design, analysis, interpretation of data or manuscript preparation for the study.

\section{Availability of data and materials}

The dataset analyzed during the current study is available in the Oncomine repository, doi:10.1038/nature10983 [34]

\section{Authors' contributions \\ STB designed the study, performed and analyzed the majority of experiments, and wrote the manuscript. KAG performed and aided in analysis of quantitative PCR experiments. CEG carried out all cell sorting experiments. JWF provided experimental and technical assistance in acquisition of data. SRM supervised the study and provided reagents. MK designed and supervised the study, performed experiments and wrote the manuscript. All authors read and approved the final manuscript.}

\section{Competing interests}

The authors declare that they have no competing interests.

\section{Consent for publication}

Not applicable.

\section{Ethics approval and consent to participate}

The University of Adelaide institutional animal ethics committee approved all mouse studies.

Received: 17 October 2016 Accepted: 18 January 2017

Published online: 31 January 2017

\section{References}

1. Visvader JE, Lindeman GJ. Cancer stem cells: current status and evolving complexities. Cell Stem Cell. 2012;10:717-28.
2. Al-Hajj M, Wicha MS, Benito-Hernandez A, Morrison SJ, Clarke MF. Prospective identification of tumorigenic breast cancer cells. Proc Natl Acad Sci U S A. 2003;100:3983-8.

3. Palacios-Arreola MI, Nava-Castro KE, Castro Jl, Garcia-Zepeda E, Carrero JC, Morales-Montor J. The role of chemokines in breast cancer pathology and its possible use as therapeutic targets. J Immunol Res. 2014;2014:849720.

4. Kochetkova M, Kumar S, McColl SR. Chemokine receptors CXCR4 and CCR7 promote metastasis by preventing anoikis in cancer cells. Cell Death Differ. 2009:16:664-73.

5. Cunningham HD, Shannon LA, Calloway PA, Fassold BC, Dunwiddie I, Vielhauer G, Zhang M, Vines CM. Expression of the C-C chemokine receptor 7 mediates metastasis of breast cancer to the lymph nodes in mice. Transl Oncol. 2010;3:354-61.

6. Andre F, Cabioglu N, Assi H, Sabourin JC, Delaloge S, Sahin A, Broglio K, Spano JP, Combadiere C, Bucana C, et al. Expression of chemokine receptors predicts the site of metastatic relapse in patients with axillary node positive primary breast cancer. Ann Oncol. 2006;17:945-51.

7. Boyle ST, Ingman WV, Poltavets V, Faulkner JW, Whitfield RJ, McColl SR, Kochetkova M. The chemokine receptor CCR7 promotes mammary tumorigenesis through amplification of stem-like cells. Oncogene. 2016; 35(1):105-15.

8. Sale S, Lafkas D, Artavanis-Tsakonas S. Notch2 genetic fate mapping reveals two previously unrecognized mammary epithelial lineages. Nat Cell Biol. 2013;15:451-60.

9. Artavanis-Tsakonas S, Rand MD, Lake RJ. Notch signaling: cell fate control and signal integration in development. Science. 1999;284:770-6.

10. Lobry C, Oh P, Mansour MR, Look AT, Aifantis I. Notch signaling: switching an oncogene to a tumor suppressor. Blood. 2014;123:2451-9.

11. Papayannidis C, DeAngelo DJ, Stock W, Huang B, Shaik MN, Cesari R, Zheng X, Reynolds JM, English PA, Ozeck M, et al. A Phase 1 study of the novel gammasecretase inhibitor PF-03084014 in patients with T-cell acute lymphoblastic leukemia and T-cell lymphoblastic lymphoma. Blood Cancer J. 2015:5:e350.

12. Olsauskas-Kuprys R, Zlobin A, Osipo C. Gamma secretase inhibitors of Notch signaling. Onco Targets Ther. 2013;6:943-55.

13. Ayyanan A, Civenni G, Ciarloni L, Morel C, Mueller N, Lefort K, Mandinova A, Raffoul W, Fiche M, Dotto GP, Brisken C. Increased Wnt signaling triggers oncogenic conversion of human breast epithelial cells by a Notchdependent mechanism. Proc Natl Acad Sci U S A. 2006;103:3799-804.

14. Guo S, Liu M, Gonzalez-Perez RR. Role of Notch and its oncogenic signaling crosstalk in breast cancer. Biochim Biophys Acta. 1815;2011:197-213.

15. Previs RA, Coleman RL, Harris AL, Sood AK. Molecular pathways: translational and therapeutic implications of the Notch signaling pathway in cancer. Clin Cancer Res. 2015;21:955-61.

16. Baker AT, Zlobin A, Osipo C. Notch-EGFR/HER2 bidirectional crosstalk in breast cancer. Front Oncol. 2014:4:360.

17. McGowan PM, Simedrea C, Ribot EJ, Foster PJ, Palmieri D, Steeg PS, Allan AL, Chambers AF. Notch1 inhibition alters the CD44hi/CD24lo population and reduces the formation of brain metastases from breast cancer. Mol Cancer Res. 2011:9:834-44.

18. Dontu G, Jackson KW, McNicholas E, Kawamura MJ, Abdallah WM, Wicha MS. Role of Notch signaling in cell-fate determination of human mammary stem/progenitor cells. Breast Cancer Res. 2004;6:R605-615.

19. Ling H, Sylvestre JR, Jolicoeur P. Notch1-induced mammary tumor development is cyclin D1-dependent and correlates with expansion of premalignant multipotent duct-limited progenitors. Oncogene. 2010:29:4543-54.

20. Boyle ST, Faulkner JW, McColl SR, Kochetkova M. The chemokine receptor CCR6 facilitates the onset of mammary neoplasia in the MMTV-PyMT mouse model via recruitment of tumor-promoting macrophages. Mol Cancer. 2015;14:115.

21. Holland JD, Kochetkova M, Akekawatchai C, Dottore M, Lopez A, McColl SR. Differential functional activation of chemokine receptor CXCR4 is mediated by $\mathrm{G}$ proteins in breast cancer cells. Cancer Res. 2006:66:4117-24.

22. Shackleton M, Vaillant F, Simpson KJ, Stingl J, Smyth GK, Asselin-Labat ML, Wu L, Lindeman GJ, Visvader JE. Generation of a functional mammary gland from a single stem cell. Nature. 2006;439:84-8.

23. Ma J, Lanza DG, Guest I, Uk-Lim C, Glinskii A, Glinsky G, Sell S. Characterization of mammary cancer stem cells in the MMTV-PyMT mouse model. Tumour Biol. 2012:33:1983-96.

24. Dontu G, Abdallah WM, Foley JM, Jackson KW, Clarke MF, Kawamura MJ, Wicha MS. In vitro propagation and transcriptional profiling of human mammary stem/progenitor cells. Genes Dev. 2003;17:1253-70. 
25. Debeb BG, Cohen EN, Boley K, Freiter EM, Li L, Robertson FM, Reuben JM, Cristofanilli M, Buchholz TA, Woodward WA. Pre-clinical studies of Notch signaling inhibitor RO4929097 in inflammatory breast cancer cells. Breast Cancer Res Treat. 2012;134:495-510

26. Buonamici S, Trimarchi T, Ruocco MG, Reavie L, Cathelin S, Mar BG, Klinakis A, Lukyanov Y, Tseng JC, Sen F, et al. CCR7 signalling as an essential regulator of CNS infiltration in T-cell leukaemia. Nature. 2009;459:1000-4.

27. Grudzien P, Lo S, Albain KS, Robinson P, Rajan P, Strack PR, Golde TE, Miele $L$, Foreman KE. Inhibition of Notch signaling reduces the stem-like population of breast cancer cells and prevents mammosphere formation. Anticancer Res. 2010;30:3853-67.

28. Clevers H, Loh KM, Nusse R. Stem cell signaling. An integral program for tissue renewal and regeneration: Wnt signaling and stem cell control. Science. 2014;346:1248012.

29. Zeng YA, Nusse R. Wnt proteins are self-renewal factors for mammary stem cells and promote their long-term expansion in culture. Cell Stem Cell. 2010;6:568-77.

30. Mirandola L, Chiriva-Internati M, Montagna D, Locatelli F, Zecca M, Ranzani M, Basile A, Locati M, Cobos E, Kast WM, et al. Notch1 regulates chemotaxis and proliferation by controlling the CC-chemokine receptors 5 and 9 in T cell acute lymphoblastic leukaemia. J Pathol. 2012;226:713-22.

31. Mirandola L, Apicella L, Colombo M, Yu Y, Berta DG, Platonova N, Lazzari E, Lancellotti M, Bulfamante G, Cobos E, et al. Anti-Notch treatment prevents multiple myeloma cells localization to the bone marrow via the chemokine system CXCR4/SDF-1. Leukemia. 2013;27:1558-66.

32. Tsuyada A, Chow A, Wu J, Somlo G, Chu P, Loera S, Luu T, Li AX, Wu X, Ye W, et al. CCL2 mediates cross-talk between cancer cells and stromal fibroblasts that regulates breast cancer stem cells. Cancer Res. 2012;72:2768-79

33. Raju R, Gadakh S, Gopal P, George B, Advani J, Soman S, Prasad TS, Girijadevi R. Differential ligand-signaling network of CCL19/CCL21-CCR7 system. Oxford: Database; 2015.

34. Curtis C, Shah SP, Chin SF, Turashvili G, Rueda OM, Dunning MJ, Speed D, Lynch AG, Samarajiwa S, Yuan Y, et al. The genomic and transcriptomic architecture of 2,000 breast tumours reveals novel subgroups. Nature. 2012;486:346-52.

35. Kondratyev M, Kreso A, Hallett RM, Girgis-Gabardo A, Barcelon ME, llieva D, Ware C, Majumder PK, Hassell JA. Gamma-secretase inhibitors target tumorinitiating cells in a mouse model of ERBB2 breast cancer. Oncogene. 2012;31:93-103

36. Sharma A, Paranjape AN, Rangarajan A, Dighe RR. A monoclonal antibody against human Notch1 ligand-binding domain depletes subpopulation of putative breast cancer stem-like cells. Mol Cancer Ther. 2012;11:77-86.

\section{Submit your next manuscript to BioMed Central and we will help you at every step:}

- We accept pre-submission inquiries

- Our selector tool helps you to find the most relevant journal

- We provide round the clock customer support

- Convenient online submission

- Thorough peer review

- Inclusion in PubMed and all major indexing services

- Maximum visibility for your research

Submit your manuscript at www.biomedcentral.com/submit

) Biomed Central 